\title{
Suppression of plagioclase and clinopyroxene nucleation in a basaltic magma: Insights from real- time synchrotron tomography
}

N. LE GALL ${ }^{1 *}, \mathrm{~F} \cdot \mathrm{ARZILLI}^{2}, \mathrm{~B} \cdot \mathrm{CAI}^{3}, \mathrm{M} \cdot \mathrm{POLACCI}^{2}, \mathrm{~N}$. $\mathrm{VO}^{4}$, G. LA SPINA ${ }^{2}$, M. HARTLEY ${ }^{2}$, R. C. ATWOOD ${ }^{4}$, D. Di GENOVA ${ }^{5}$, S. NONNI ${ }^{6}$, E. LLEWELLIN ${ }^{7}$, M. BURTON ${ }^{2}$, P.D. $\mathrm{LEE}^{1 *}$

${ }^{1}$ UCL Mechanical Enginering, Research Complex at Harwell, Didcot, OX11 0FA, UK

${ }^{2}$ Department of Earth and Environmental Sciences, University of Manchester, Manchester, M13 9PL, UK

${ }^{3}$ School of Metallurgy and Materials, University of Birmingham, Birmingham, B15 2TT, UK

${ }^{4}$ Diamond Light Source Ltd., Didcot, OX11 0DE, UK

${ }^{5}$ Institute of Non-Metallic Materials, Clausthal University of Technology, 38678 Clausthal-Zellerfeld, Germany

${ }^{6}$ University of Manchester at Harwell, Didcot,OX11 0DE, UK

${ }^{7}$ Department of Earth Sciences, Durham University, Durham, DH1 3LE, UK

*correspondence: n.gall@ucl.ac.uk, peter.lee@ucl.ac.uk

Synchrotron X-ray microtomography experiments were performed to investigate the influence of temperature-time paths on the nucleation and growth of plagioclase and clinopyroxene in an oxidized, nominally anhydrous basaltic magma. Cooling-induced crystallisation experiments have been carried out in air, at atmospheric pressure and temperatures from 1250 to $1100{ }^{\circ} \mathrm{C}$, using a bespoke hightemperature resistance furnace. Two types of cooling were applied: (1) a large drop of temperature followed by a dwell step of 4 hours and (2) a continuous cooling, producing two different crystal phases (either (1) clinopyroxene or (2) plagioclase phenocrysts). The textural evolution of charges revealed that suppression of crystal nucleation can be due to changes in the melt composition with increasing undercooling and time. This study provides a basis for models of the viscosity of crystal-bearing basaltic melts and its influence on the emplacement of lava flows. 